\title{
ESTUDO DO COMPORTAMENTO REOLÓGICO DE ESPESSANTES NATURAIS APLICADOS NA ESTAMPARIA TÊXTIL.
}

\author{
J.B. GIORDANO. ${ }^{1}$ \\ ${ }^{1}$ Faculdade Tecnologia de Americana, Departamento Têxtil \\ E-mail para contato: jbgiordano@uol.com.br.
}

\begin{abstract}
RESUMO: A estamparia têxtil é o processo que permite aplicar desenho no tecido, utilizando-se espessantes sintéticos ou naturais para formulação de pastas que são coloridas. O objetivo deste trabalho é estudar do comportamento reológico dos espessantes naturais para determinar em que condições se devem manipulá-los, verificar os que têm melhor desempenho na estamparia e maior estabilidade ao tempo e temperatura. Neste trabalho foram utilizados espessantes naturais a base de alginato de sódio, guar e tamarindo, para formulação de pasta de estampar com corantes reativos e dispersos. A partir destas pastas, foram medidas as viscosidades em função do tempo e temperatura. Em seguida, foram coloridas e estampadas, verificando-se quais dos espessantes tiveram melhor desempenho na estamparia. O bom desempenho é considerado se o espessante: não interferir na cor; fácil remoção dele pós estampagem; compatível com os corantes e os demais produtos que compõe a pasta de estampar; boa estabilidade ao tempo e temperatura. $\mathrm{O}$ espessante de alginato de sódio apresenta menor estabilidade ao tempo e temperatura, porém o tecido final estampado com este espessante possui melhor qualidade, pois os outros mesmo após sucessivas lavagens apresentam resíduos de espessantes.
\end{abstract}

\section{INTRODUÇÃO:}

A estamparia têxtil é o processo que permite aplicar um desenho numa superfície têxtil, aumentando o valor agregado do produto final. Basicamente, existem dois métodos de aplicação de cor na superfície têxtil. Um deles utiliza corantes que reagem quimicamente com a fibra e para cada fibra têxtil, há um grupo de corante específico. Este método é semelhante a um tingimento, assim, se obtém os mesmos tecidos, vários tingimentos em áreas diferentes resultando em um desenho. Outro método utiliza pigmentos, como estes não possuem grande afinidade com as fibras têxteis, precisam ser fixados por intermédio de resinas as quais irão formas um filme sobre o tecido. (Araujo 1986).

No processo de estamparia, se utiliza para transporte e fixação de pigmentos e corantes no tecido, uma mistura de várias substâncias a qual se denomina como pasta, na estamparia. Essa apresenta uma viscosidade específica e comportamento reológico para bom desempenho no processo. 
Na preparação da pasta uma das substâncias mais importante é o espessante o qual pode ser de origem natural ou sintética, este produto é o responsável pela viscosidade da pasta, que durante o processo de estampagem, deve permanecer constante para evitar estampas com defeitos de processo.

O principal objetivo é estudar o comportamento reológico dos espessantes naturais aplicados na indústria têxtil. Esse será alcançado a partir da formulação de pasta de estamparia utilizando espessantes naturais, verificação de qual será o melhor desempenho, tanto na intensidade da cor como na durabilidade da pasta, verificação do efeito da temperatura e tempo na viscosidade das pastas, observação da degradação das pastas à ação de radiação ultravioleta e conclusão de qual espessante resultará em um toque mais agradável ao tecido. (Ameida e Hirschler 1996)

\subsection{Espessantes: (Costa 1996)}

A presença de espessante na pasta de estampar é essencial para evitar que os corantes migrem para outras partes. Ele atua desde a deposição da pasta sobre o tecido até a fixação do corante. Devem ser eliminados por lavagem ou evaporação.

A propriedade fundamental dos espessantes é a viscosidade, a qual é variável conforme a solicitação aplicada.

\section{$\underline{\text { Funções dos espessantes: }}$}

Suas funções são pontuadas em:

- Veículo de transporte do corante ou pigmento e produtos químicos auxiliares;

- Elevação da viscosidade das pastas, evitando-se o fenômeno da migração, tanto durante o processo de estampagem quanto no processo de secagem;

- Retém o corante seco não fixado ao tecido (a formação de uma película que também protege contra a ação mecânica);

- Absorve umidade durante o processo de vaporização;

- Colóide de proteção contra precipitação de corantes.

Espessantes Naturais: (Neves 20000

\section{Alginato de sódio}

São polímeros dos ácidos D-manurônico e D-glucorônico, obtidos das algas marinhas marrons, Phacophyceae. 
Os alginatos obtidos de diferentes algas marinhas apresentam diferenças no teor de ácidos manurônico e glucorônico acarretando variações nos géis produzidos. Sendo que aqueles com frações ricas em ácido glucorônico constituem géis mais fortes e quebradiços. Produtos extraídos de algas marinhas são praticamente os únicos que são compatíveis com os corantes reativos. Grande utilização em tecidos contendo algodão ou celulose regenerada; são incompatíveis a sais metálicos bem como meio alcalino.

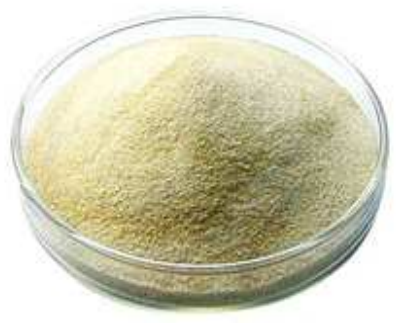

Figura 1: Alginato de sódio

\section{Tamarindo (Vanderlei 1995)}

É um polissacarídio de polímero natural originário da Tamarindus indica, árvore africana cultivada na Índia. O pó da semente de tamarindo é de $300 \%$ mais eficiente que o amido de milho e mais econômico. As sementes quando processadas são utilizadas como estabilizantes de sucos, alimentos industrializados e como goma (cola) para tecidos ou papel.

\section{Guar (Vanderlei 1995)}

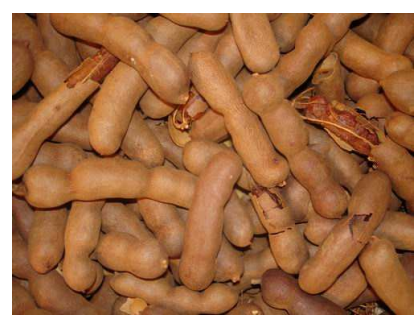

Figura 2: Tamarindo

Goma obtida das sementes da planta nativa da Índia Cyamopsis tetragonolobus ou proraloides. Ela é polímero orgânico natural com capacidade espessante e dispersantes utilizados em cremes e loções, xampus e condicionadores. Apresentam a forma de pó que devem ser dispersos em água antes do uso. É utilizado como espessante, estabilizante e emulsificante. 


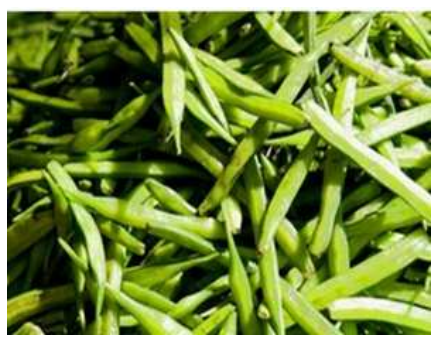

Figura 3: Guar

\section{EXPERIMENTAL:}

\subsection{Materiais e equipamentos:}

\section{Materiais:}

- Tecido de algodão e de poliéster. Espessantes a base alginato de sódio, guar e tamarindo. Quadro serigráfico. Corantes reativos e corantes dispersos. Carbonato de sódio, uréia, anti espuma a base de silicone, sulfato de amônio.

\section{Equipamentos:}

- Agitador tipo hélice para homogeneização dos espessantes, balança, estufa com controle de tempo e temperatura, viscosímetro do tipo cilindros concêntricos.

\subsection{Metodologia}

\section{Preparação das pastas:}

- Foram dissolvidos os espessantes naturais, individualmente, em água sob agitação nas seguintes proporções: alginato de sódio a 4\%, guar e tamarindo a $8 \%$ e em seguida, estas soluções permaneceram em repouso a temperatura ambiente $\left(25^{\circ} \mathrm{C}\right)$ para completa homogeneização;

- Mediu-se a viscosidade destes espessantes em função do tempo em dias acondicionados a temperatura de $25^{\circ} \mathrm{C}$ e $5^{\circ} \mathrm{C}$;

- Preparam-se pastas de estampar com corantes reativos e dispersos com estes espessantes naturais de acordo com as quantidades a seguir:

Pasta reativo:

Pasta Disperso

830g Epessante natural $150 \mathrm{~g}$ Uréia

$\frac{20 \mathrm{~g} \mathrm{C}}{1000 \mathrm{~g}}$
$885 \mathrm{~g}$ Espessante natural

$100 \mathrm{~g}$ Uréia

$10 \mathrm{~g}$ Sulfato de amônio

$5 \mathrm{~g}$ Anti espuma 
- Nas pastas preparadas foram adicionados os corantes reativos e dispersos (amarelo, azul e vermelho) nas proporções $8 \%$ para os corantes reativos e $2 \%$ para os corantes dispersos;

- As pastas coloridas foram estampadas em tecidos de algodão com os corantes reativos e em poliéster com os corantes dispersos;

- Após estampagem, os tecidos estampados foram secos a temperatura ambiente $\left(25^{\circ} \mathrm{C}\right) \mathrm{em}$ seguida, fixados a $150^{\circ} \mathrm{C}$ por $5 \mathrm{~min}$. para os corantes reativos e $2 \mathrm{~min}$. a $180^{\circ} \mathrm{C}$ para os corantes dispersos:

- Depois de fixados, os tecidos estampados foram submetidos a uma serie de 4 lavagens sucessivas com água a temperatura de ebulição para remoção de corantes não fixados e dos espessantes naturais, em seguida, foram secos a temperatura ambiente $\left(25^{\circ} \mathrm{C}\right)$.

\section{RESULTADOS E DISCUSSÕES:}

\subsection{Medidas de viscosidade:}

A seguir são apresentados os resultados da viscosidade em cps dos espessantes naturais em função do tempo em dias mantidos a $25^{\circ} \mathrm{C}$ e $5^{\circ} \mathrm{C}$.

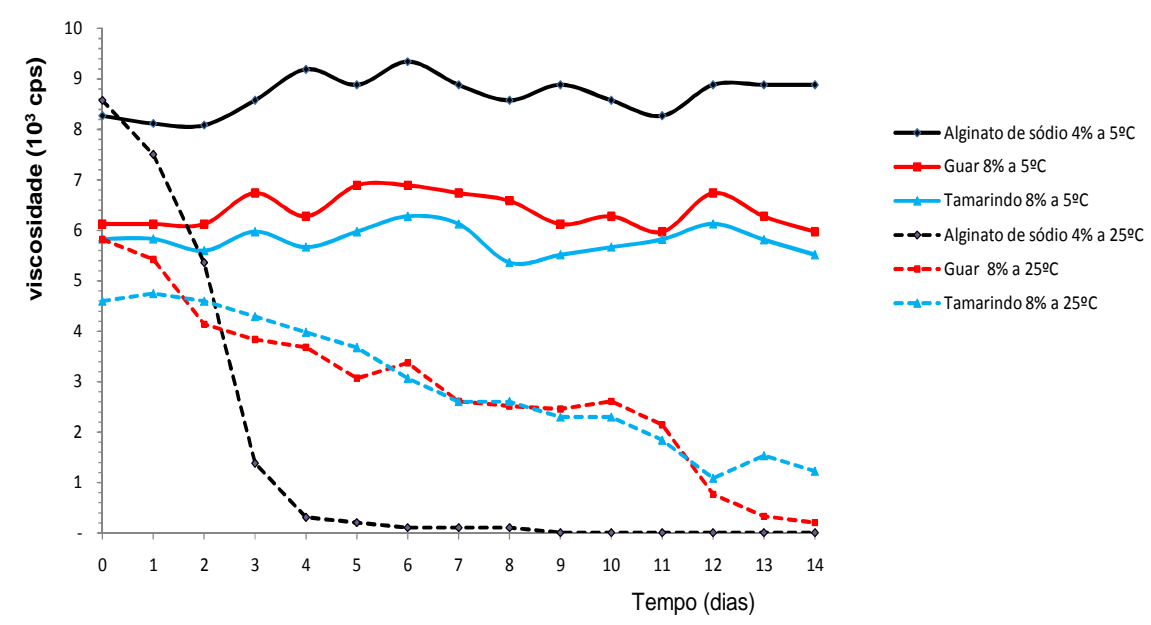

Figura 4: Gráfico de viscosidade (cps) de espessantes naturais em função do tempo (dias) mantidos a $25^{\circ} \mathrm{C}$ e $5^{\circ} \mathrm{C}$. 
Observa-se que no gráfico da figura 4 que o espessante a base de alginato de sódio possui maior poder de aumentar a viscosidade, pois mesmo dissolvido a $4 \%$ obteve-se valores maiores de viscosidade que os outros espessantes a base de Guar a $8 \%$ e Tamarindo a $8 \%$.

Os espessantes acondicionados a temperatura ambiente $\left(25^{\circ} \mathrm{C}\right)$ tendem a diminuir a viscosidade ao longo dos dias, sendo que o espessante a base de alginato de sódio é mais sensível a temperatura, haja vista que a partir do $3^{\circ}$ dia ocorre considerável perda de viscosidade, o que o torna nestas condições impróprias para o uso na estamparia. Os outros espessantes, Guar e Tamarindo iniciam-se esta queda de viscosidade a partir do $12^{\circ}$ dia. Mantendo-se os espessantes a temperatura de $5^{\circ} \mathrm{C}$ é observado que ocorre maior estabilidade quanto a viscosidade destas substâncias.

\subsection{Tecidos estampados sobre algodão com corantes reativos utilizando espessantes} naturais:

TECIDOS ESTAMPADOS COM CORANTES REATIVOS UTILIZANDO ESPESSANTES NATURAIS

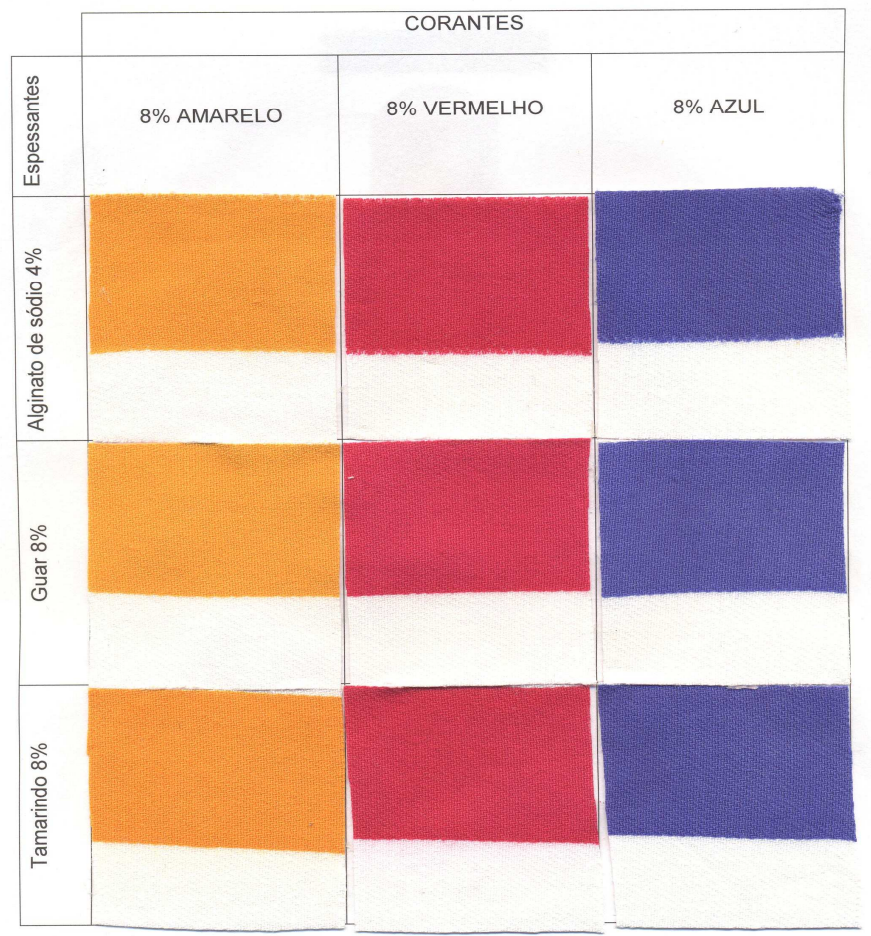

Figura 5: Tecidos estampados com corantes reativos (amarelo 8\%, vermelho 8\% e azul 8\%) utilizando os espessantes naturais: alginato de sódio 4\%, Guar $8 \%$ e Tamarindo $8 \%$. 


\subsection{Tecidos estampados sobre poliéster com corantes dispersos utilizando espessantes} naturais:

TECIDOS ESTAMPADOS COM CORANTES DISPERSOS UTILIZANDO ESPESSANTES NATURAIS

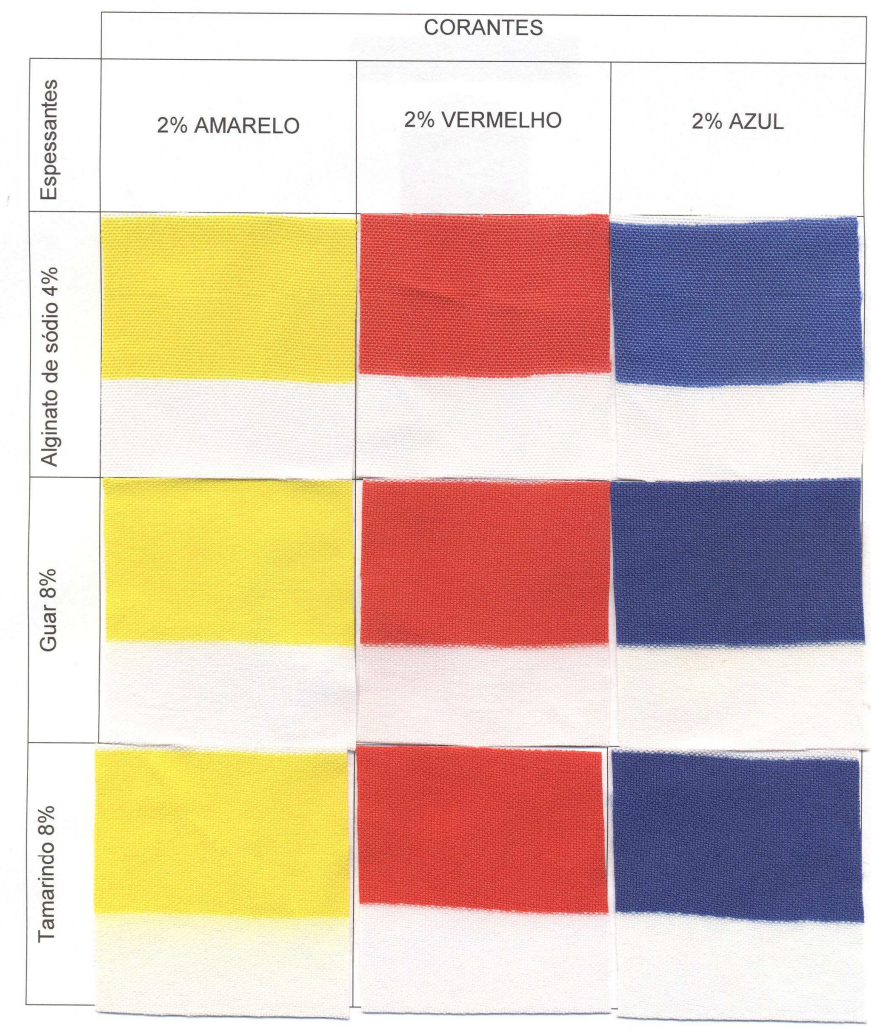

Figura 6: Tecidos estampados sobre poliéster com corantes dispersos (2\% Amarelo, $2 \%$ Vermelho e 2\% Azul) utilizando espessantes naturais: Alginato de sódio 4\%.Guar $8 \%$ e Tamarindo $8 \%$

Tanto na figura 5 como na figura 6 não se observa alterações significativas nas cores. $\mathrm{Na}$ figura 6 se observa, no entanto, que houve pequena migração do corante para parte branca não estampada, principalmente nos corantes amarelo e vermelho em pastas preparadas com o espessante a base de guar e tamarindo, isso se deve principalmente pelo fato destas pastas possuírem menor viscosidade daquela preparada com alginato de sódio.

Nestas figuras não é possível verificar se após as lavagens, os tecidos estampados apresentaram resíduos de espessantes. Agora, analisando as amostra, através da sensibilidade ao 


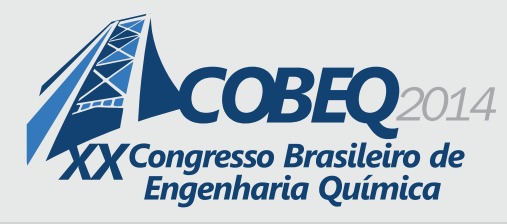

19 a 22 de outubro de 2014

Florianópolis/SC

toque, observou-se que os tecidos estampados com o espessante a base de alginato de sódio, apresentaram maior suavidade, indicando que não possuí na sua superfície resíduos de espessantes, isto se justifica no sentido que, na preparação dos espessantes utiliza-se apenas $4 \%$ de alginato de sódio, enquanto que os demais espessantes, no caso o Guar e o Tamarindo se utilizam $8 \%$, ficando mais difícil sua eliminação, mais acentuado na estampas com corantes disperso, pois a temperatura de $180{ }^{\circ} \mathrm{C}$ utilizada para a fixação dos corantes, isto contribui também para solidificação destes espessantes na superfície do tecido, necessitando dessa forma maior quantidade e lavagens para eliminação total dos espessantes.

Apesar de baixa estabilidade do espessante a base de alginato de sódio, ele é bastante utilizado na estamparia com corantes reativos, pois não interfere nas cores e é de fácil remoção após estampagem, já para os corantes dispersos se utiliza bastante os espessantes à base de guar e tamarindo, porém nestes casos é necessário aumentar a concentração dos espessantes para evitar a migração do corante. Com o alto teor de sólidos (acima de 8\%) possibilitará obter melhor contorno nos desenhos, porém será necessário maior número de lavagens para remoção completa do espessante.

\section{CONCLUSÕES:}

- Os espessantes naturais são sensíveis a temperatura de armazenamento ambiente $\left(25^{\circ} \mathrm{C}\right.$, sendo que o alginato de sódio é mais sensível que os demais espessantes naturais;

- Os espessantes naturais acondicionados a temperatura de $5^{\circ} \mathrm{C}$ são mais estáveis;

- O espessante alginato de sódio tem maior poder de espessamento;

- O espessante alginato de sódio é o mais indicado na estampagem com corantes reativos;

- Os espessantes Guar e Tamarindo são mais indicados para estampagem com corantes dispersos.

\section{REFERÊNCIAS BIBLIGRÁFICAS:}

- ARAUjO, MÁRIO de CASTRO, E. M. de Melo. Manual De Engenharia Têxtil. V.2. Fundação Calouste Gulbenkian. Lisboa. Portugal, 1986. 948 P..

- L. R. ALMEIDA e. R. HIRSCHLER. Revista Química Têxtil: "Controle de viscosidade" Ano XIX Dez 1996. Revista número: 45 pag.24 a 28;

Apostila para laboratório de aplicação Sandoz S. A .Ano XVII Jun 1995. Revista número: 39

- M. R. COSTA Revista Química Têxtil: "Estampados com pigmento teoria e prática" Uniquímica S. A . Peru Ano XIX Mar 1996. Revista número: 42

- NEVES J. Manual de estamparia têxtil. Escola de engenharia da Universidade do Minho, Julho, 2000. P. 158.

- VANDERLEI, J. S. Dispersões líquidas, nova tecnologia de espessantes sintéticos para estamparia. Revista Química Têxtil. Junho 1995. p 48 - 53. 